\title{
Article \\ Modeling of Self-Assembled Peptide Nanotubes and Determination of Their Chirality Sign Based on Dipole Moment Calculations
}

\author{
Vladimir Bystrov ${ }^{1, *(1)}$, Alla Sidorova ${ }^{2}$, Aleksey Lutsenko ${ }^{2}$, Denis Shpigun ${ }^{2}$, Ekaterina Malyshko ${ }^{2}{ }^{(0)}$, \\ Alla Nuraeva ${ }^{3}$, , Pavel Zelenovskiy ${ }^{3,4}\left(\mathbb{D}\right.$, Svitlana Kopyl ${ }^{4}$ (D) and Andrei Kholkin ${ }^{3,4,5}$ (D) \\ 1 Institute of Mathematical Problems of Biology, The Branch of Keldysh Institute of Applied Mathematics, RAS, \\ 142290 Pushchino, Russia \\ 2 Faculty of Physics, Lomonosov Moscow State University, 119991 Moscow, Russia; sky314bone@mail.ru (A.S.); \\ aleksluchrus@yandex.ru (A.L.); denish.den@mail.ru (D.S.); katyamalyshko@mail.ru (E.M.) \\ 3 School of Natural Sciences and Mathematics, Ural Federal University, 620000 Ekaterinburg, Russia; \\ allanuraeva@gmail.com (A.N.); zelenovskiy@urfu.ru (P.Z.); kholkin@ua.pt (A.K.) \\ 4 Department of Physics \& CICECO-Aveiro Institute of Materials, University of Aveiro, \\ 3810-193 Aveiro, Portugal; svitlanakopyl@ua.pt \\ 5 Physical Materials Science and Composite Materials Centre, Research School of Chemistry \& Applied \\ Biomedical Sciences, National Research Tomsk Polytechnic University, 634050 Tomsk, Russia \\ * Correspondence: vsbys@mail.ru or bystrov@impb.ru
}

\section{check for}

updates

Citation: Bystrov, V.; Sidorova, A.; Lutsenko, A.; Shpigun, D.; Malyshko, E.; Nuraeva, A.; Zelenovskiy, P.; Kopyl, S.; Kholkin, A. Modeling of Self-Assembled Peptide Nanotubes and Determination of Their Chirality Sign Based on Dipole Moment Calculations. Nanomaterials 2021, 11, 2415. https://doi.org/10.3390/ nano11092415

Academic Editor: Angelina Angelova

Received: 31 July 2021

Accepted: 9 September 2021

Published: 16 September 2021

Publisher's Note: MDPI stays neutral with regard to jurisdictional claims in published maps and institutional affiliations.

Copyright: (c) 2021 by the authors. Licensee MDPI, Basel, Switzerland. This article is an open access article distributed under the terms and conditions of the Creative Commons Attribution (CC BY) license (https:/ / creativecommons.org/licenses/by/ $4.0 /)$.

\begin{abstract}
The chirality quantification is of great importance in structural biology, where the differences in proteins twisting can provide essentially different physiological effects. However, this aspect of the chirality is still poorly studied for helix-like supramolecular structures. In this work, a method for chirality quantification based on the calculation of scalar triple products of dipole moments is suggested. As a model structure, self-assembled nanotubes of diphenylalanine (FF) made of L- and D-enantiomers were considered. The dipole moments of FF molecules were calculated using semi-empirical quantum-chemical method PM3 and the Amber force field method. The obtained results do not depend on the used simulation and calculation method, and show that the D-FF nanotubes are twisted tighter than L-FF. Moreover, the type of chirality of the helix-like nanotube is opposite to that of the initial individual molecule that is in line with the chirality alternation rule general for different levels of hierarchical organization of molecular systems. The proposed method can be applied to study other helix-like supramolecular structures.
\end{abstract}

Keywords: dipeptides; diphenylalanine; helical structures; peptide nanotubes; self-assembly; molecular modeling; dipole moments; polarization; chirality

\section{Introduction}

Self-assembly of biomolecules such as amino acids, nucleotide bases, phospholipids, and oligo- and polypeptides is the basis for the formation of DNA, molecular motors, viruses, and many other biological systems [1-4]. Biomimetic self-assembly is also a promising bottom-up approach for nanomaterials design in nanobiotechnology [5,6]. Helical self-organizing structures of different levels of hierarchical organization is an often result of such self-assembly $[1,4,5,7,8]$. Among them, $\alpha$-helices, a common type of regular secondary structure of many proteins, are the simplest and most energetically favorable structures [1,6]. For natural proteins consisting of L-amino acids, a chirality sign alternation from the "left-handed" type to the "right-handed" is observed at different levels of hierarchical organization [9-12]. In the case of DNA, the sequence of the chirality sign is "right-handed deoxyribose carbohydrate"-"left-handed nucleotides"-" right-handed DNA double helix"-"left-handed superhelix" with the increasing complexity of their level of organization. This feature of chirality is one of the key points in the hierarchy and self-organization of any biological system [9-12]. 
Despite the concept of chirality, in its qualitative sense, being widespread in natural sciences, its quantitative aspects (the magnitude and sign of chirality) are still poorly studied [13-24]. In structural biology, it is of great importance to obtain the quantitative estimates of the magnitude of chirality and the chirality sign to compare both molecular constructs with the same symmetry type and those with different types of the symmetry. The problem still lacks a solution, although many studies have been performed in the field. The detailed analysis of these studies can be found in [23].

Recently, a new method for the chirality quantification based on the scalar triple product of three consecutive vectors connecting $\mathrm{C} \alpha$ carbon atoms of neighboring amino acid residues in the polypeptide helical or superhelical structures was proposed [21-24]. Despite this approach being successfully applied to a variety of proteins [24] taken from the Protein Data Bank [25], until now it has not been used for helix-like supramolecular structures such as peptide nanotubes.

Peptide nanotubes (PNTs) is an important example of helix-like self-organizing supramolecular systems $[5,26,27]$. Peptides and their derivatives were recognized recently as biological and bio-inspired building blocks for the construction of various advanced functional materials for nanotechnology and biomedicine [28,29]. Short, linear peptides containing aromatic amino acid residues such as phenylalanine (F, H-Phe-OH) attract special attention due to their ability to mimic the self-organizing behavior of more complex proteins [26].

The simplest aromatic dipeptide capable to form helix-like nanotubes is diphenylalanine (FF, H-Phe-Phe-OH) [30-40]. Each turn of such helix PNT consists of six FF molecules (Figure 1). Fast self-assembly of such PNTs occurs in aqueous media, and the variation of external conditions allows tuning the PNT's growth rate, length, and their physical properties $[33,38,39,41-45]$. FF PNTs possess a wide range of useful functional properties $[41,46-48]$ that make them promising material for various applications in nanotechnology [33,41,46-50], nanoelectronics [28,35,48,51,52], and biomedicine [34-36,47,50,53-55].

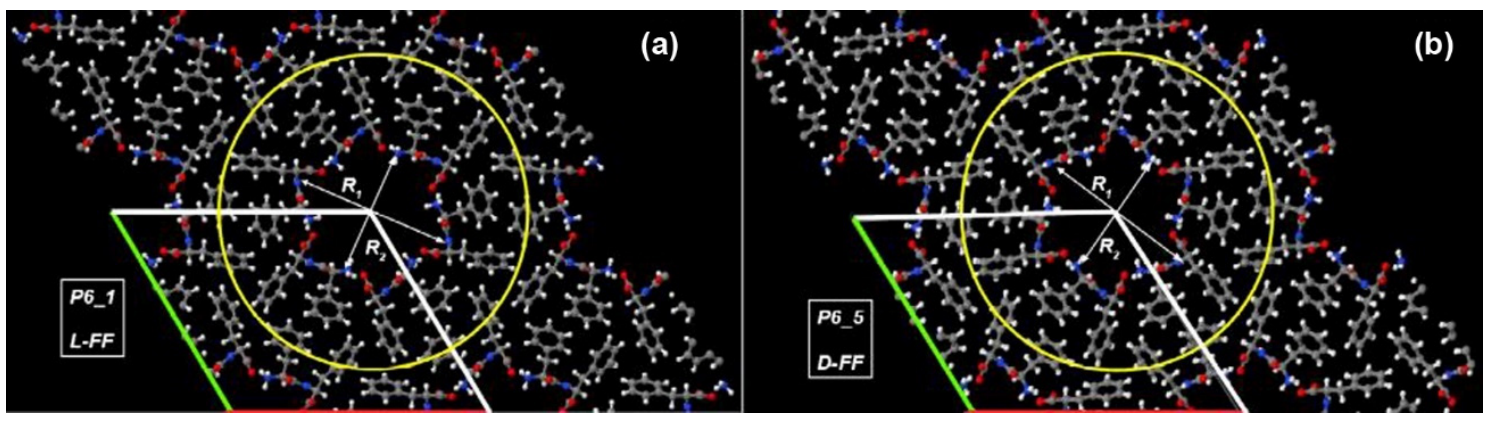

Figure 1. Images of molecular crystals composed of: (a) L-FF PNTs (space group P6 1 ), and (b) D-FF PNTs (space group P65). Hexagonal unit cells are marked with green, red, and white lines. The individual PNTs in crystal are highlighted by yellow circles. Atom colors: oxygen—red, nitrogen—blue, carbon-grey, and hydrogen—white.

The effect of chirality of FF molecules on the self-assembly and properties of PNTs has recently been studied in detail both experimentally and by computer simulation [37,38,42,56-59]. Lattice cell parameters for PNT made of "right-handed" FF molecules (H-D-Phe-D-Phe-OH, abbreviated hereafter D-FF) are close to those for PNTs made of "left-handed" FF molecules (H-L-Phe-L-Phe-OH, abbreviated hereafter L-FF), but their space groups are different [38]. Due to the difference of FF monomers chirality, the L-FF PNTs belong to the P6 $6_{1}$ space group, whereas D-FF PNTs belong to the $\mathrm{P} 6_{5}$. This $\mathrm{P}_{1}-\mathrm{P} 6_{5}$ pair is one of 11 pairs of enantiomorphic space groups [60] that are distinguished by the twisting direction of their 6-fold screw axis [61]. It was also shown that "left-handed" L-FF molecules form "righthanded" helix-like PNTs, whereas "right-handed" D-FF molecules form "left-handed" PNTs distinguished with their intermolecular interaction energies, self-assembly kinetics, and characteristic lengths [30,38]. 
In this work, we demonstrated that the method for chirality quantification proposed recently for protein helical structures $[23,24]$ can be adopted for analysis of helix-like self-assembled PNTs. For the calculation of magnitude and sign of the chirality of L-FF and D-FF PNTs a set of sequential vectors of individual dipole moments of FF molecules comprising the turn of each helix of PNTs was used. The dipole moments were calculated using the HyperChem software [62].

\section{Models Details and Computational Methods}

\subsection{Main Models and Used Software}

Recently, we studied the structure and properties of empty L-FF and D-FF PNTs, as well as those with inner cavity filled with water molecules [56,57]. As water molecules do not affect the chirality of the PNTs, in this work, we considered empty (anhydrous) PNTs to simplify the calculations. The initial models of the PNTs were constructed using the same approach as in [56,57] based on X-ray crystallographic data for L-FF PNT (CCDC 16337, work [31]) and for D-FF PNT (CCDC 1853771, work [38]) taken from Cambridge Crystallographic Data Center (CCDC) [63]. The structural optimization and calculations were carried out using the density functional theory (DFT) methods (in Vienna Ab initio Simulation Package (VASP) program [64]), taking into account the Van der Waals interactions by "PBE + D3" method. The resulted molecular structures visualized by CCDC Mercury [65] are presented in Figure 1, whereas their main crystallographic parameters are summarized in Table 1.

Table 1. Experimental lattice cell parameters for L-FF [31] and D-FF [38] PNTs and inner cavity sizes $R_{1}, R_{2}[56]$.

\begin{tabular}{ccc}
\hline & L-FF & D-FF \\
\hline Space group & P6 $6_{1}$ & P6 5 \\
\hline$a, \AA$ & 24.0709 & 23.9468 \\
\hline$b, \AA$ & 24.0709 & 23.9468 \\
\hline$c, \AA$ & 5.4560 & 5.4411 \\
\hline$V, \AA^{3}$ & 2737.7 & 2702.2 \\
\hline$R_{1}, \AA$ & 15.3 & 15.2 \\
\hline$R_{2}, \AA$ & 12.2 & 12.1 \\
\hline
\end{tabular}

\subsection{Models of FF Nanotubes}

The molecular structures of both L-FF and D-FF PNTs were converted using OpenBabel software [66] from * .cif to *.hin format for their further analysis and calculations of their polar properties with various molecular mechanical and quantum-mechanical semi-empirical methods in HyperChem package [62] (Figure 2). These structures contain two coils of the helix arranged along with the $c$ axis. Each coil consists of 6 FF molecules (258 atoms) and coils are separated with a lattice constant $c$ around $5.45 \AA$ [56]. The repetition of the coils along the c-axis leads to the formation of PNT with the corresponding chirality: right-handed helix for L-FF and left-handed helix for D-FF (Figure 3). 

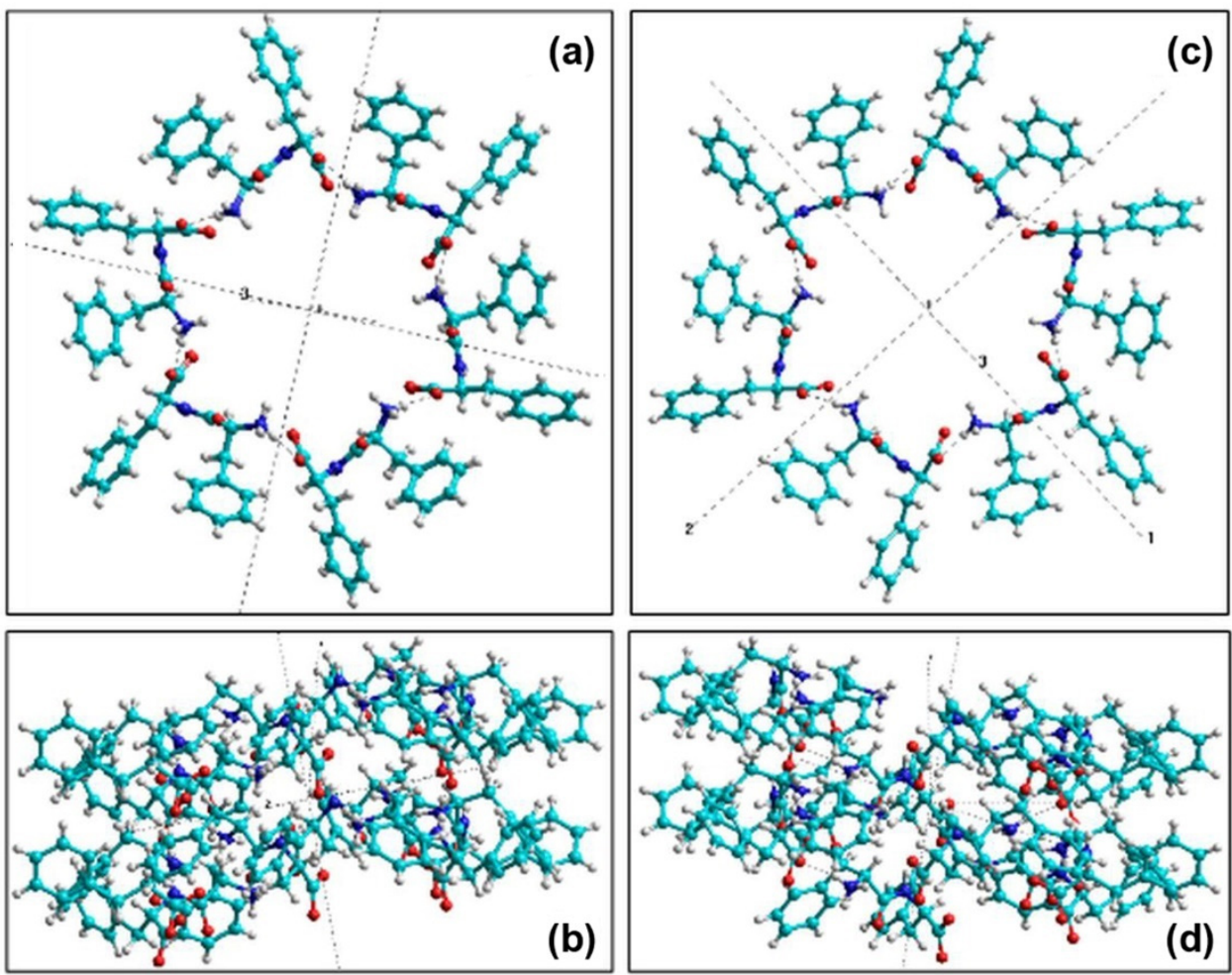

Figure 2. Two coils of FF PNT in HyperChem workspace based on experimental crystallographic data [31,38]: (a) L-FF in the Z-plane, (b) L-FF in the Y-plane, (c) D-FF in the Z-plane, and (d) D-FF in the Y-plane.
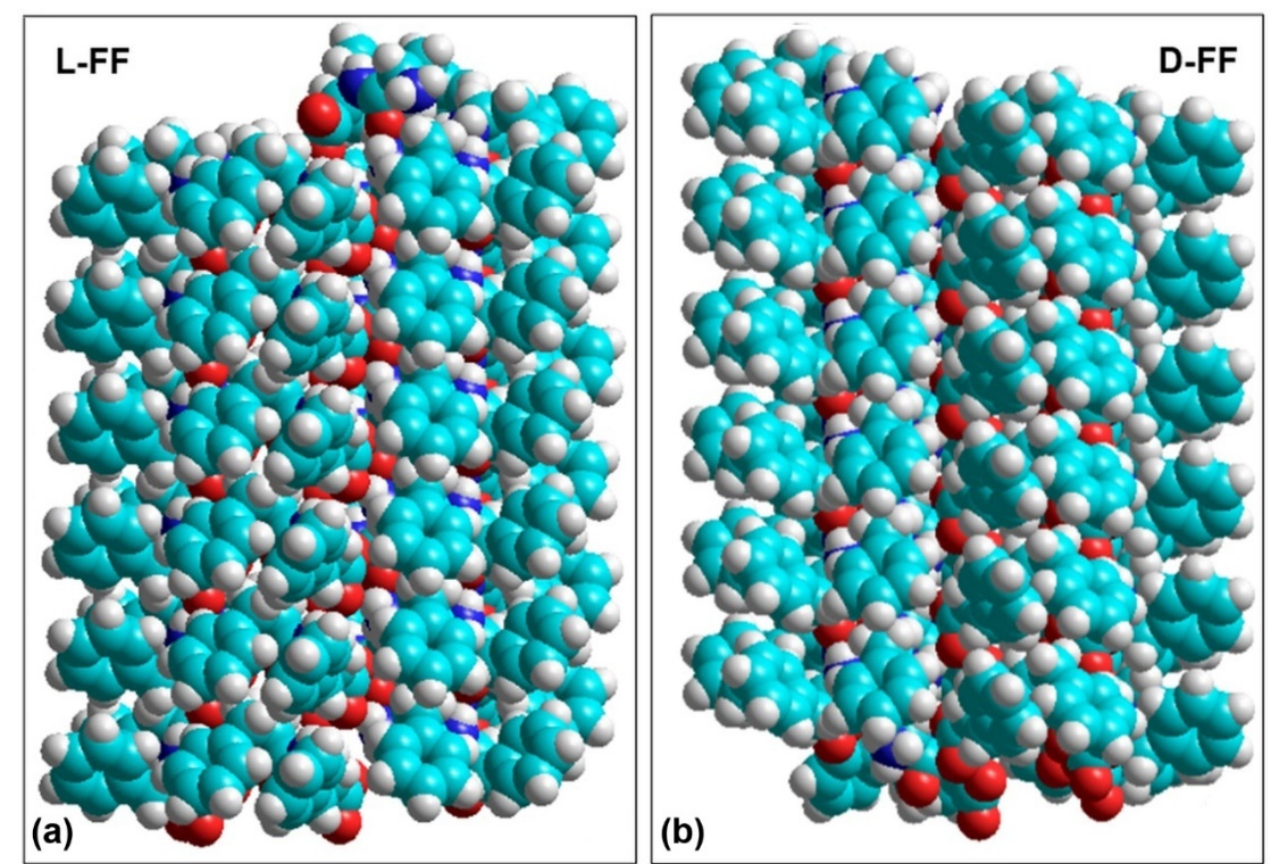

Figure 3. Images of helix-like FF PNTs based on experimental crystallographic data [31,38]: (a) L-FF and (b) D-FF. L-FF PNT shows right-handed twist, whereas D-FF shows left-handed.

It is known that water molecules in PNT nanochannels can affect both the structure and properties of the PNTs $[41,44,56,57]$. Therefore, in this work we considered in more detail the empty (anhydrous) nanotubes (Figure 1) to better understand how the dipole 
moments of FF molecules form the helix-like PNT with different chiralities and quantify the chirality.

The dipole moments, $\mathbf{D}_{i}$, of L-FF and D-FF molecules and corresponding helix-like structures were calculated using the semi-empirical quantum-mechanical method PM3 in the restricted Hartree-Fock approximation (RHF) and molecular mechanical force field method Amber from the HyperChem package [62]. Previous studies [37,38,42] have shown that for the dipole moments and energy calculated with other methods AM1 and BIOCHARM are similar to those obtained by PM3 and Amber. Therefore, in this work we used only PM3 and Amber methods. The calculated values of the dipole moments for individual L-FF and D-FF molecules are presented in Table 2. They are similar to the results obtained and analyzed earlier [30,37,38,42], and correspond well to the molecules orientation in experimentally observed helix-like structures.

Table 2. The dipole moments and some other structural parameters of individual L-FF and D-FF molecules calculated by PM3 method.

\begin{tabular}{ccccccccc}
\hline Molecule & $\begin{array}{c}\text { Dx, } \\
\text { Debye }\end{array}$ & $\begin{array}{c}\text { Dy, } \\
\text { Debye }\end{array}$ & $\begin{array}{c}\text { Dz, } \\
\text { Debye }\end{array}$ & $\begin{array}{c}\text { Dtot, } \\
\text { Debye }\end{array}$ & $\begin{array}{c}\text { Van der Waals } \\
\text { Volume, } \AA^{3}\end{array}$ & $\begin{array}{c}\text { Polarization, } \\
\text { C/m }^{2}\end{array}$ & $\begin{array}{c}\text { Total } \\
\text { Energy, a.u. }\end{array}$ & $\begin{array}{c}\text { RMS } \\
\text { Gradient, } \\
\text { a.u./Å }\end{array}$ \\
\hline L-FF & 11.645 & 1.115 & 0.899 & 11.733 & 291.919 & 0.134 & -133.959 & $\sim 0.06$ \\
\hline D-FF & -11.630 & 1.052 & 1.113 & 11.730 & 291.977 & 0.134 & -133.959 & $\sim 0.07$ \\
\hline
\end{tabular}

\section{Results and Discussions}

In contrast to $\alpha$-helix proteins, supramolecular PNTs are comprised of individual FF molecules held by relatively weak hydrogen bonds [31-33]. Therefore, the chirality quantification method developed earlier for protein structures [21-24] cannot be directly applied for PNTs and requires some adaptations.

Briefly, the original method considered a helical polypeptide chain consisting of $n$ amino acid residues, and a set of $(n-1)$ vectors $\mathbf{v}_{i}$ was built between each two adjacent $\mathrm{C} \alpha$ atoms in amino acid residues (Figure 4). For each three consecutive vectors, their scalar triple product was calculated:

$$
\left(\left[\mathbf{v}_{1}, \mathbf{v}_{2}\right], \mathbf{v}_{3}\right)=\left(y_{1} z_{2}-y_{2} z_{1}\right) x_{3}+\left(z_{1} x_{2}-z_{2} x_{1}\right) y_{3}+\left(x_{1} y_{2}-x_{2} y_{1}\right) z_{3}
$$

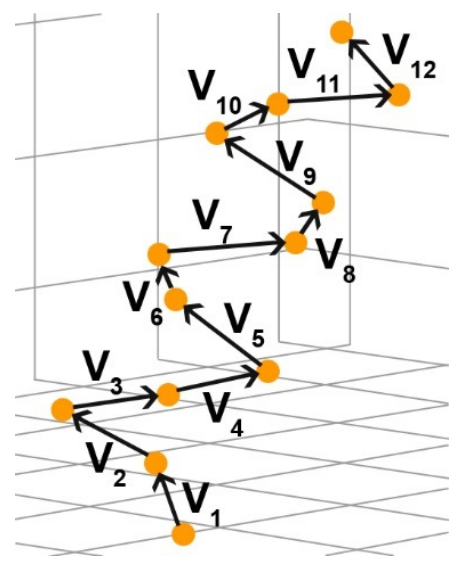

Figure 4. Graphical representation of vectors between neighboring $\mathrm{C} \alpha$ atoms in a helical protein used for calculating a scalar triple product.

The sum of all these scalar triple products (see Equation (2)) allowed us to estimate the chirality sign. If $\chi_{\text {total }}$ is positive, the structure is right-handed; for left-handed structures, 
$\chi_{\text {total }}$ is negative $[23,24]$. This method has been validated for almost 1000 proteins $[23,24]$ taken from the Protein Data Bank [25].

$$
\chi_{\text {total }}=\sum_{i=1}^{n-3}\left(\left[\mathbf{v}_{i}, \mathbf{v}_{i+1}\right], \mathbf{v}_{i+2}\right)
$$

In this work, the abovementioned approach was adopted for analysis of supramolecular FF PNTs. Instead of vectors between adjacent $\mathrm{C} \alpha$ atoms, a scalar triple product of dipole moments $\mathbf{D}_{i}$ of the successive individual FF molecules constituting a turn of the PNT helix-like nanotube was used. The origin of $\mathbf{D}_{i}$ vectors is taken relative to the center of mass of the corresponding molecules. The absolute value of each dipole moment $\mathbf{D}_{i}$ is

$$
D_{i}=\left|\mathbf{D}_{i}\right|=\sqrt{D_{x, i}^{2}+D_{y, i}^{2}+D_{z, i}^{2}}
$$

where $D_{x, i}, D_{y, i}$, and $D_{z, i}$ are the components of the $i$-th vector $\mathbf{D}_{i}$ in the Cartesian coordinates. Similar to Equation (2), the sum of the scalar triple products of the dipole moments related to the PNT's chirality can be written as:

$$
c_{\text {total }}=\sum_{i=1}^{n-2}\left(\left[\mathbf{D}_{i}, \mathbf{D}_{i+1}\right], \mathbf{D}_{i+2}\right) .
$$

It is necessary to note that the summation here is taken over $i$ in the range from 1 to $(n-2)$, whereas in Equation (2), the $i$ range is from 1 to $(n-3)$. This is because in supramolecular helixes $i$ numerates the individual molecules instead of the $C \alpha$ atoms in proteins. The $c_{\text {total }}$ can be normalized over the average value of the total dipole momentum of the PNT's coil, $D_{a v}=\frac{1}{6} \sum_{i=1}^{6} D_{i}$, to find a universal measure of the chirality:

$$
c_{\text {norm }}=\frac{c_{t o t a l}}{D_{a v}^{3}} .
$$

Individual dipole moments of FF molecules in one coil of helix-like PNTs were obtained using semiempirical PM3 method in restricted Hartree-Fock (RHF) approximation and molecular mechanic Amber method (after PM3) implemented in HyperChem software [62]. The results are presented below in Tables 3 and 4 for L-FF and for D-FF, respectively. Schematic representation of the spatial arrangement of FF individual dipole moments $\mathbf{D}_{i}$ in two coils of PNTs are shown in Figure $5 \mathrm{a}, \mathrm{b}$ for L-FF and in Figure $5 \mathrm{c}, \mathrm{d}$ for

\begin{tabular}{|c|c|c|c|c|c|c|c|c|}
\hline \multirow{2}{*}{$i$} & \multicolumn{4}{|c|}{ PM3 RHF } & \multicolumn{4}{|c|}{ Amber } \\
\hline & $D i$ & $D x$ & $D y$ & $D z$ & $D i$ & $D x$ & $D y$ & $D z$ \\
\hline 1 & 24.022 & 14.576 & -15.421 & -11.261 & 23.458 & 14.901 & -15.250 & -9.781 \\
\hline 2 & 22.549 & -6.313 & -18.923 & -10.513 & 21.734 & -6.280 & -18.879 & -8.748 \\
\hline 3 & 22.389 & -18.646 & -3.636 & -11.849 & 21.545 & -18.698 & -3.629 & -10.070 \\
\hline 4 & 22.381 & -11.564 & 14.461 & -12.573 & 21.530 & -11.695 & 14.495 & -10.801 \\
\hline 5 & 22.441 & 7.555 & 17.308 & -12.123 & 21.578 & 7.397 & 17.408 & -10.384 \\
\hline 6 & 22.587 & 18.767 & 2.568 & -12.303 & 21.638 & 18.581 & 2.745 & -10.742 \\
\hline Dcoil & 70.851 & 4.376 & -3.643 & -70.622 & 60.752 & 4.206 & -3.109 & -60.526 \\
\hline$D a v$ & 22.728 & 0.729 & -0.607 & -11.770 & 21.914 & 0.701 & -0.518 & -10.088 \\
\hline
\end{tabular}
D-FF PNTs.

Table 3. Values of dipole moments for a coil of the helix-like L-FF PNT computed using PM3 (RHF) and Amber (after PM3) methods. All values of dipole moments are given in Debye units. 
Table 4. Values of dipole moments for a coil of the helix-like D-FF PNT computed using PM3 (RHF) and Amber (after PM3) methods. All values of dipole moments are given in Debye units.

\begin{tabular}{ccccccccc}
\hline \multirow{2}{*}{$\boldsymbol{i}$} & \multicolumn{9}{c}{ PM3 RHF } & \multicolumn{3}{c}{ Amber } \\
\cline { 2 - 9 } & $\boldsymbol{D} \boldsymbol{D}$ & $\boldsymbol{D}$ & $\boldsymbol{D} \boldsymbol{D}$ & $\boldsymbol{D} \boldsymbol{D}$ & $\boldsymbol{D} \boldsymbol{D}$ & $\boldsymbol{D x}$ & $\boldsymbol{D y}$ & -15.170 \\
\hline 1 & 22.523 & -12.228 & -15.267 & -11.167 & 21.707 & -12.299 & -9.475 \\
\hline 2 & 22.340 & 7.302 & -18.014 & -11.072 & 21.527 & 7.210 & -17.995 & -9.360 \\
\hline 3 & 22.372 & 19.234 & -2.597 & -11.125 & 21.520 & 19.168 & -2.656 & -9.416 \\
\hline 4 & 22.475 & 11.905 & 15.905 & -11.290 & 21.625 & 11.914 & 15.274 & -9.612 \\
\hline 5 & 22.629 & -6.613 & 17.478 & -12.761 & 21.703 & -6.487 & 17.386 & -11.256 \\
\hline 6 & 23.855 & -19.820 & 4.382 & -12.531 & 23.271 & -19.893 & 4.727 & -11.112 \\
\hline Dcoil & 69.971 & -0.218 & 1.888 & -69.945 & 60.253 & -0.387 & 1.565 & -60.231 \\
\hline Dav & 22.704 & -0.036 & 0.315 & -11.658 & 21.892 & -0.064 & 0.261 & -10.038 \\
\hline
\end{tabular}
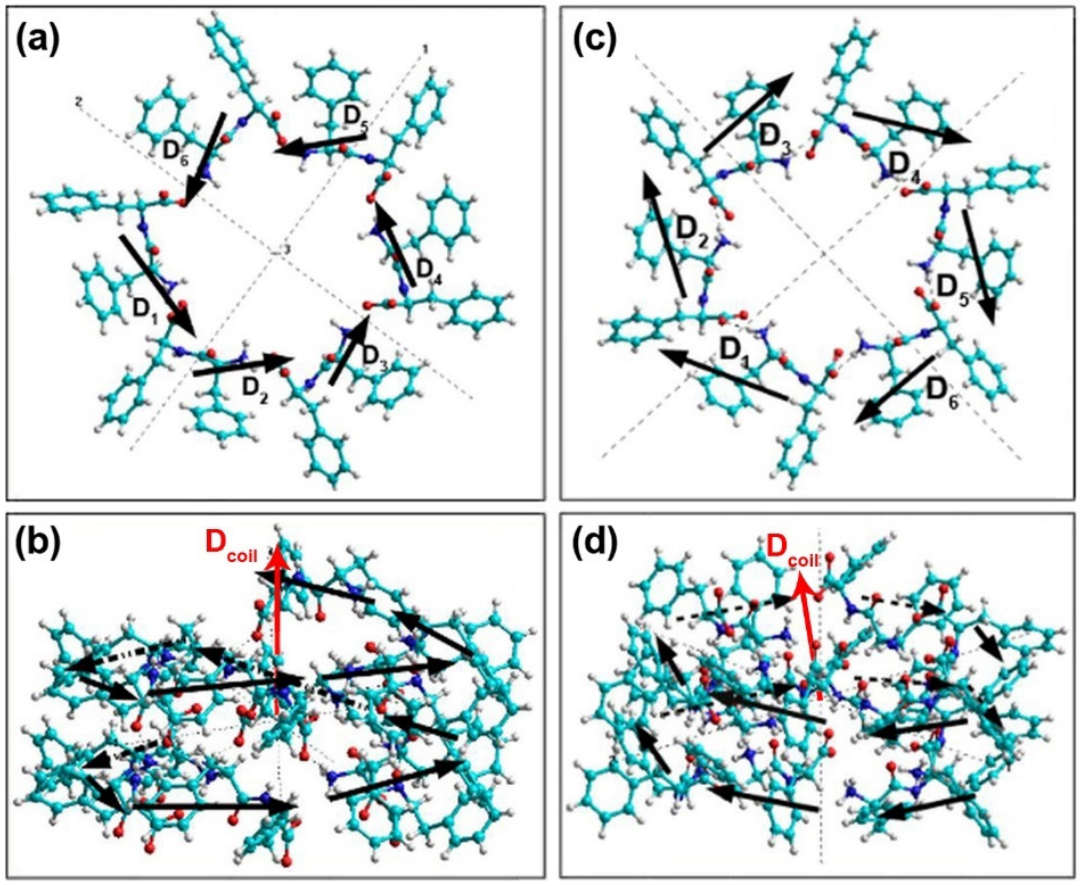

Figure 5. Schematic presentation of dipole moments $D_{i}$ in two coils of $(\mathbf{a}, \mathbf{b})$ L-FF and $(\mathbf{c}, \mathbf{d})$ D-FF PNTs: $(\mathbf{a}, \mathbf{c})$ Z-plane projection, (b,d) Y-plane projection. For L-FF PNT dipole moments form a right-hand helix, whereas for D-FF PNT form a left-hand helix. Red arrows show the directions of the total dipole moments of the coil $\mathbf{D}_{\text {coil }}$.

It is important to note that, due to the helix-like structure of PNT, the dipole moment $\mathbf{D}_{i}$ of each next FF molecule in the coil is rotated by $\sim 60^{\circ}$ in the XOY plane. Therefore, at a full vector rotation at 360 degrees in a coil, the components $D_{i, x}$ and $D_{i, y}$ almost compensate for one another. Thus, the $x$ and $y$ components of the total dipole moment of the coil, $D_{\text {coil }}$, are much smaller than $D_{c o i l, z}$, which is always oriented along the OZ axis and increases $D_{\text {coil }}$ (Tables 3 and 4 ). As a result, the total dipole moment of a coil $D_{\text {coil }}$ is directed mainly along OZ axis with slight deviations (Figure 5), which corresponds to the previously obtained data $[30,37,38,56,57]$.

It is worth noting that, in contrast to the original chirality quantification method developed for proteins [21-24], where the vectors were built between the carbon atoms C $\alpha$ of each subsequent amino acid, in the current modification of the method, the vector of the dipole moment of each FF molecule in the PNT is taken relative to the center of mass of the 
corresponding molecule. The origin of $\mathbf{D}_{i}$ is a point in space defined by the vector $\mathbf{r}_{D i}$ with components $\left\{x_{D i} ; y_{D i} ; z_{D i}\right\}$ calculated as follows:

$$
\begin{aligned}
& x_{D i}=\left\{\sum_{j=1}^{N} m_{j} \cdot x_{j}\right\} /\left\{\sum_{j=1}^{N} m_{j}\right\}, \\
& y_{D i}=\left\{\sum_{j=1}^{N} m_{j} \cdot y_{j}\right\} /\left\{\sum_{j=1}^{N} m_{j}\right\}, \\
& z_{D i}=\left\{\sum_{j=1}^{N} m_{j} \cdot z_{j}\right\} /\left\{\sum_{j=1}^{N} m_{j}\right\} .
\end{aligned}
$$

Here, $m_{j}, x_{j}, y_{j}$, and $z_{j}$ are the mass and coordinates, respectively, of the $j$-th atom in the $i$-th FF molecule in the PNT, and $N=43$ is the number of atoms in one FF molecule. For example, the coordinates of the center of mass for the first FF molecule $(i=1)$ in a coil of L-FF PNT (Figure 6) are:

$$
x_{D 1}=2.35 \AA ; y_{D 1}=-7.80 \AA ; z_{D 1}=1.02 \AA .
$$

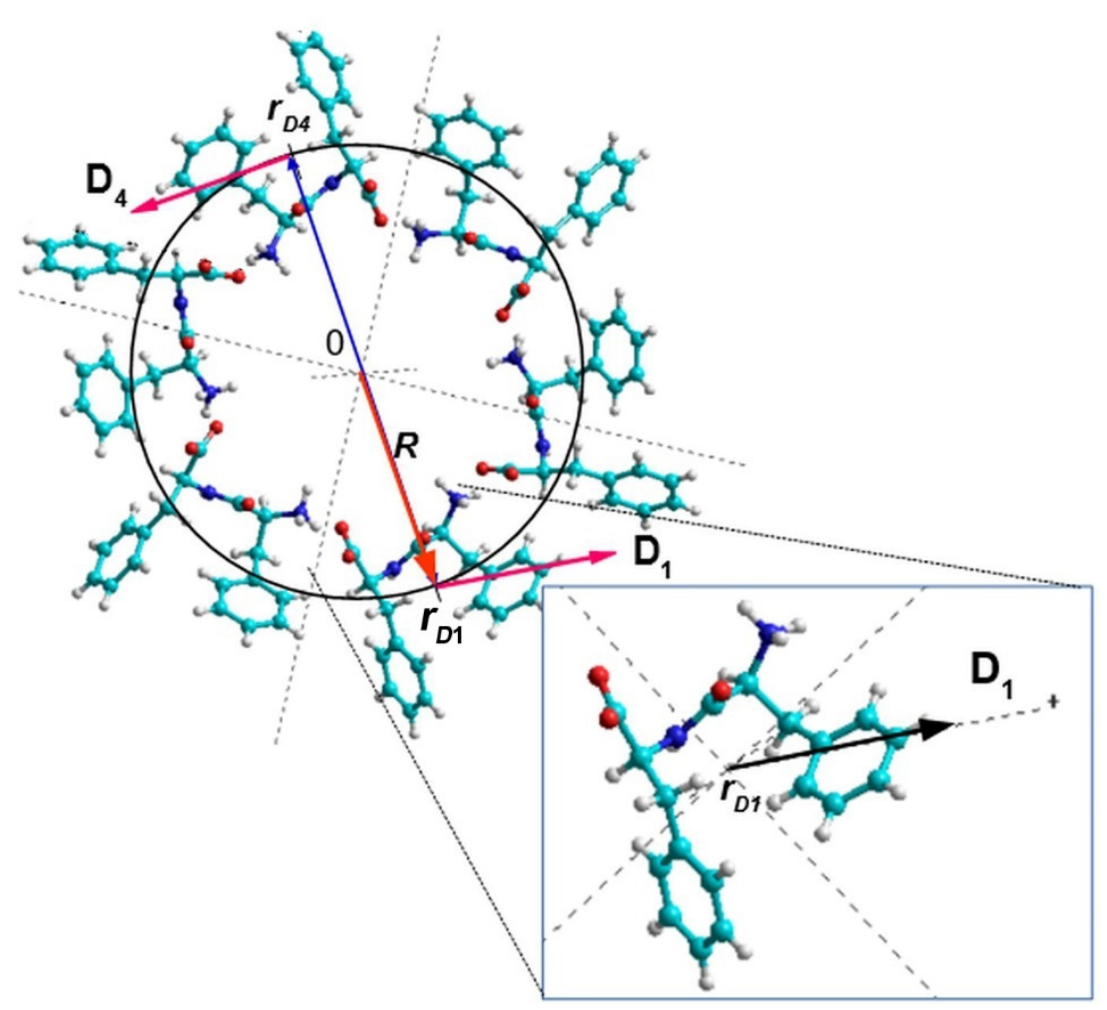

Figure 6. A coil of L-FF PNT with vectors $\mathbf{r}_{\mathrm{D} 1}$ and $\mathbf{r}_{\mathrm{D} 4}$ pointing the centers of mass of individual FF molecules with dipole moments $\mathbf{D}_{1}$ and $\mathbf{D}_{4}$, correspondingly.

This point is the origin for the $\mathbf{D}_{1}$ dipole moment vector. Similarly, the origins for other vectors $\mathbf{D}_{i}$ can be calculated. As a result, dipole moments form a helix with a pitch equal to $c=5.456 \AA$ (for L-FF, $c=5.441 \AA$ for D-FF PNTs), and the helix radius $R$ is about $8.15 \AA$ for L-FF PNT.

The obtained values of the dipole moments for L-FF and D-FF PNTs allow us to quantify their chiralities following the Equations (4) and (5). The calculated magnitudes of the PNTs chirality, $c_{\text {total }}$, and the normalized chirality, $c_{\text {norm }}$, are presented in Table 5 . For each type of PNT, both PM3 and Amber methods $c_{\text {total }}$ demonstrate close values with the divergence about $15 \%$, whereas for $c_{\text {norm }}$ the divergence is less than $5 \%$. Therefore, $c_{\text {norm }}$ can be considered as a universal value for chirality quantification that does not depend on the calculation method. 
Table 5. Magnitudes and signs of the chirality obtained for L-FF and D-FF PNTs for various calculating methods.

\begin{tabular}{|c|c|c|c|c|}
\hline \multirow{2}{*}{$\begin{array}{c}\text { Type of PNT } \\
\text { Calculating Method }\end{array}$} & \multicolumn{2}{|c|}{ L-FF } & \multicolumn{2}{|c|}{ D-FF } \\
\hline & PM3 & Amber & PM3 & Amber \\
\hline$c_{\text {total }}$, Debye $^{3}$ & $16,034.82$ & $13,870.71$ & $-14,497.03$ & $-12,161.23$ \\
\hline$c_{\text {norm }}$ & 1.37 & 1.32 & -1.23 & -1.16 \\
\hline Chirality sign & positive & positive & negative & negative \\
\hline Chirality symbol & $\mathrm{D}$ & $\mathrm{D}$ & $\mathrm{L}$ & $\mathrm{L}$ \\
\hline
\end{tabular}

At the same time, the absolute value of $c_{\text {norm }}$ for L-FF PNT is about $10 \%$ higher than that for D-FF PNT. This difference exceeds the calculation error and thus shows the difference in PNTs chiralities. Lower $c_{\text {norm }}$ value observed for D-FF PNTs indicates that this PNT is twisted tighter than L-FF. This is also confirmed by the lower volume of the D-FF PNT unit cell (Table 1).

Following the original method [23,24], the sign of the $c_{\text {norm }}$ corresponds to the PNT's chirality type. For L-FF PNT, $c_{\text {norm }}$ is positive thus this PNT should be right-handed, whereas negative $c_{\text {norm }}$ value for D-FF PNT indicates its left-handed twisting. This result is confirmed by the previous crystallographic studies [31,38] and the individual dipole moments completely follow this arrangement (Figure 5). It is worth noting that the chirality alternating observed earlier for natural proteins and DNA [9-12] preserves in the supramolecular PNTs as well. The type of chirality of the helix-like PNT is opposite to that of the individual dipeptide. This fact also can be a confirmation of the adequacy of the proposed method for supramolecular PNTs chirality quantification.

\section{Conclusions}

A method for quantification of the chirality of self-assembled helix-like FF nanotubes based on the scalar triple products of the individual FF molecules dipole moments is described. The dipole moments were calculated for nanotubes comprised of L-FF and D-FF molecules by quantum-chemical and molecular mechanics methods, and the independence of the magnitude and the sign of the chirality on the calculation method is demonstrated. The obtained magnitudes of the chirality for L-FF nanotubes are about $10 \%$ higher than those of L-FF, which indicates that D-FF nanotubes are twisted tighter than L-FF. The alternating of the chirality type observed earlier for natural proteins and DNA also preserves in the supramolecular PNTs. The type of chirality of the helix-like PNT is opposite to that of the individual dipeptide. This effect is in line with the chirality alternation rule, general for different levels of hierarchical organization of molecular systems, and additionally corroborates the validity of the proposed method.

The extension of the chirality quantification method to supramolecular helix-like nanostructures opens new facilities for comparing both molecular constructs of the same chirality type and those with different constructs. Moreover, it provides an opportunity to reveal the physical basis for the chirality sign formation, which is associated with the electrostatic dipole-dipole interaction of individual molecules. This approach can be applied to study other helical and helix-like supramolecular structures.

Author Contributions: V.B., A.S. and P.Z. wrote the manuscript. A.K. and E.M. supervised and supported this study. E.M. also developed the concept of chirality. A.L. and D.S. performed the calculations. S.K., A.N. and P.Z. participated in the experimental data processing and data analysis. All authors have read and agreed to the published version of the manuscript.

Funding: This research was funded by the Russian Foundation for Basic Research, grant n. 19-01-00519-a.

Institutional Review Board Statement: Not applicable.

Informed Consent Statement: Not applicable. 
Data Availability Statement: The data presented in this study are available on request from the corresponding author.

Acknowledgments: The authors are grateful to the Russian Foundation for Basic Researches (RFBR): grants №№ 19-01-00519_A and 20-51-53014_GFEN_A. Part of this work (A.K.) was supported by the Ministry of Science and Higher Education of the Russian Federation (grant No. 075-15-2021-588). P.Z., S.K. and A.K. are grateful to the FCT project "BioPiezo"-PTDC/CTM-CTM/31679/2017 (CENTRO-01-0145-FEDER-031679) and to the project CICECO-Aveiro Institute of Materials, refs. UIDB/50011/2020 and UIDP/50011/2020, financed by national funds through the Portuguese Foundation for Science and Technology/MCTES. Part of this work was funded by national funds (OE), through FCT-Fundação para a Ciência e a Tecnologia, I.P., in the scope of the framework contract foreseen in the numbers 4, 5, and 6 of the article 23, of the Decree-Law 57/2016, of August 29, changed by Law $57 / 2017$, of July 19. A.S. and E.M. are grateful to the the Interdisciplinary Scientific and Educational School of Moscow University "Fundamental and Applied Space Research".

Conflicts of Interest: The authors declare no conflict of interest.

\section{References}

1. Lehninger, A.L. Biochemistry-The Molecular Basis of Cell Structure and Function; Worth Publishers, Inc.: New York, NY, USA, 1972.

2. Stock, D.; Leslie, A.G.; Walker, J.E. Molecular architecture of the rotary motor in ATP synthase. Science 1999, $286,1700-1705$. [CrossRef]

3. Ban, N.; McPherson, A. The structure of satellite panicum mosaic virus at $1.9 \AA$ resolution. Nat. Struct. Biol. 1995, 2, 882-890. [CrossRef]

4. Zhang, S. Emerging biological materials through molecular self-assembly. Biotechn. Adv. 2002, 20, 321-339. [CrossRef]

5. Levin, A.; Hakala, T.A.; Schnaider, L.; Bernardes, G.J.L.; Gazit, E.; Knowles, T.P.J. Biomimetic peptide self-assembly for functional materials. Nat. Rev. Chem. 2020, 4, 615-634. [CrossRef]

6. Mendes, A.C.; Baran, E.T.; Reis, R.L.; Azevedo, H.S. Self-assembly in nature: Using the principles of nature to create complex nanobiomaterials. Wiley Interdiscip. Rev. Nanomed. Nanobiotechnol. 2013, 5, 582-612. [CrossRef] [PubMed]

7. Whitesides, G.M.; Mathias, J.P.; Seto, C.T. Molecular self-assembly and nanochemistry: A chemical strategy for the synthesis of nanostructures. Science 1991, 254, 1312-1319. [CrossRef] [PubMed]

8. Mandal, D.; Shirazi, A.N.; Parang, K. Self-assembly of peptides to nanostructures. Org. Biomol. Chem. 2014, 12, 3544-3561. [CrossRef] [PubMed]

9. Tverdislov, V.A. Chirality as a primary switch of hierarchical levels in molecular biological systems. Biophysics 2013, 58, 128-132. [CrossRef]

10. Malyshko, E.V.; Tverdislov, V.A. Chirality as a physical aspect of structure formation in biological macromolecular systems. IOP J. Phys. Conf. Ser. 2016, 741, 012065. [CrossRef]

11. Tverdislov, V.A.; Malyshko, E.V. Chiral Dualism as an Instrument of Hierarchical Structure Formation in Molecular Biology. Symmetry 2020, 12, 587. [CrossRef]

12. Tverdislov, V.A.; Malyshko, E.V. On regularities in the spontaneous formation of structural hierarchies in chiral systems of nonliving and living matter. Phys.-Uspekhi 2019, 62, 354-363. [CrossRef]

13. Buda, A.B.; der Heyde, T.A.; Mislow, K. On Quantifying Chirality. Angew. Chem. Int. Ed. Engl. 1992, 31, 989-1007. [CrossRef]

14. Weinberg, N.; Mislow, K. On chirality measures and chirality properties. Can. J. Chem. 2000, 78, 41-45. [CrossRef]

15. Randic, M. Shape recognition and chirality measure: Reestablishing the link between similarity and dissimilarity in discrete space. Chemom. Intell. Lab. Syst. 1991, 10, 213-225. [CrossRef]

16. Zabrodsky, H.; Peleg, S.; Avnir, D. Continuous symmetry measures. J. Am. Chem. Soc. 1992, 114, 7843-7851. [CrossRef]

17. Mezey, P.G. Chirality Measures and Graph Representations. Comput. Math. Appl. 1997, 34, 105-112. [CrossRef]

18. Pinsky, M.; Dryzun, C.; Casanova, D.; Alemany, P.; Avnir, D. Analytical methods for calculating Continuous Symmetry Measures and the Chirality Measure. J. Comput. Chem. 2008, 29, 2712-2721. [CrossRef] [PubMed]

19. Petitjean, M. Chirality and Symmetry Measures: A Transdisciplinary Review. Entropy 2003, 5, 271-312. [CrossRef]

20. Zhao, T.; Zhang, Q.; Long, H.; Xu, L. Graph Theoretical Representation of Atomic Asymmetry and Molecular Chirality of Benzenoids in Two-Dimensional Space. PLoS ONE 2014, 9, e102043. [CrossRef]

21. Sidorova, A.E.; Malyshko, E.V.; Kotov, A.R.; Tverdislov, V.A.; Ustinin, M.N. Quantitative Criteria of Chirality in Hierarchical Protein Structures. Biophysics 2019, 64, 155-166. [CrossRef]

22. Sidorova, A.E.; Levashova, N.T.; Malyshko, E.V.; Tverdislov, V.A. Autowave Self-Organization in the Folding of Proteins. Mosc. Univ. Phys. Bull. 2019, 74, 213-226. [CrossRef]

23. Sidorova, A.E.; Lutsenko, A.O.; Shpigun, D.K.; Malyshko, E.V.; Tverdislov, V.A. Methods for Determining the Chirality sign of the Helical and Superhelical Protein Structures. Biophysics 2021, 66, 421. [CrossRef]

24. Sidorova, A.E.; Malyshko, E.V.; Lutsenko, A.O.; Shpigun, D.K.; Bagrova, O.E. Protein Helical Structures: Defining Handedness and Localization Features. Symmetry 2021, 13, 879. [CrossRef]

25. RCSB Protein Data Bank. Available online: http://www.rcsb.org (accessed on 30 August 2021). 
26. Yuan, C.; Ji, W.; Xing, R.; Li, J.; Gazit, E.; Yan, X. Hierarchically oriented organization in supramolecular peptide crystals. Nat. Rev. Chem. 2019, 3, 567. [CrossRef]

27. Hamley, I.W. Peptide Nanotubes. Angew. Chem. Int. Ed. 2014, 53, 6866-6881. [CrossRef]

28. Tao, K.; Makam, P.; Aizen, R.; Gazit, E. Self-assembling peptide semiconductors. Science 2017, 358, eaam9756. [CrossRef] [PubMed]

29. Ghadiri, M.R.; Granja, J.R.; Milligan, R.A.; McRee, D.E.; Khazanovich, N. Self-assembling organic nanotubes based on cyclic peptide architecture. Nature 1993, 366, 324-327. [CrossRef]

30. Bystrov, V.S.; Zelenovskiy, P.S.; Nuraeva, A.S.; Kopyl, S.; Zhulyabina, O.A.; Tverdislov, V.A. Chiral peculiar properties of self-organization of diphenylalanine peptide nanotubes: Modeling of structure and properties. Math. Biol. Bioinform. 2019, 14, 94-124. [CrossRef]

31. Görbitz, C.H. Nanotube formation by hydrophobic dipeptides. Chem. Eur. J. 2001, 7, 5153-5159. [CrossRef]

32. Görbitz, C.H. The structure of nanotubes formed by diphenylalanine, the core recognition motif of Alzheimer's b-amyloid polypeptide. Chem. Commun. 2006, 1, 2332-2334. [CrossRef]

33. Kim, J.; Han, T.E.; Kim, Y.; Park, J.S.; Choi, J.; Churchill, D.G.; Kim, S.O.; Ihee, H. Role of water in directing diphenylalanine assembly into nanotubes and nanowires. Adv. Mater. 2010, 22, 583-587. [CrossRef]

34. Bystrov, V.S.; Bdikin, I.; Heredia, A.; Pullar, R.C.; Mishina, E.; Sigov, A.; Kholkin, A.L. Piezoelectricity and Ferroelectricity in biomaterials: From proteins to self-assembled peptide nanotubes. In Piezoelectric Nanomaterials for Biomedical Applications; Ciofani, G., Menciassi, A., Eds.; Springer: Berlin/Heidelberg, Germany, 2012; pp. 187-211.

35. Bystrov, V.S. Computer Simulation Nanostructures: Bioferroelectric Peptide Nanotubes. Bioferroelectricity: Peptide Nanotubes; LAP Lambert Academic Publishing: Saarbruecken, Germay, 2016.

36. Bystrov, V.S.; Paramonova, E.V.; Bdikin, I.K.; Kopyl, S.; Heredia, A.; Pullar, R.C.; Kholkin, A.L. Bioferroelectricity: Diphenylalanine peptide nanotubes computational modeling and ferroelectric properties at the nanoscale. Ferroelectrics 2012, 440, 3-24. [CrossRef]

37. Bystrov, V.S.; Zelenovskiy, P.S.; Nuraeva, A.S.; Kopyl, S.; Zhulyabina, O.A.; Tverdislov, V.A. Molecular modeling and computational study of the chiral-dependent structures and properties of the self-assembling diphenylalanine peptide nanotubes. J. Mol. Modeling 2019, 25, 199. [CrossRef]

38. Zelenovskiy, P.S.; Nuraeva, A.S.; Kopyl, S.; Arkhipov, S.G.; Vasilev, S.G.; Bystrov, V.S.; Gruzdev, D.A.; Waliszek, M.; Svitlyk, V.; Shur, V.Y.; et al. Chirality-Dependent Growth of Self-Assembled Diphenylalanine Microtubes. Cryst. Growth Des. 2019, 19, 6414-6421. [CrossRef]

39. Nuraeva, A.; Vasilev, S.; Vasileva, D.; Zelenovskiy, P.; Chezganov, D.; Esin, A.; Kopyl, S.; Romanyuk, K.; Shur, V.Y.; Kholkin, A.L. Evaporation-Driven Crystallization of Diphenylalanine Microtubes for Microelectronic Applications. Cryst. Growth Des. 2016, 16, 1472-1479. [CrossRef]

40. Yuan, T.; Xu, Y.; Fei, J.; Xue, H.; Li, X.; Wang, C.; Fytas, G.; Li, J. The Ultrafast Assembly of a Dipeptide Supramolecular Organogel and its Phase Transition from Gel to Crystal. Angew. Chem. Int. Ed. 2019, 58, 11072-11077. [CrossRef] [PubMed]

41. Andrade-Filho, T.; Martins, T.C.; Ferreira, F.F.; Alves, W.A.; Rocha, A.R. Water-driven stabilization of diphenylalanine nanotube structures. Theor. Chem. Acc. 2016, 135, 185. [CrossRef]

42. Bystrov, V.S.; Kopyl, S.A.; Zelenovskiy, P.; Zhulyabina, O.A.; Tverdislov, V.A.; Salehli, F.; Ghermani, N.E.; Shur, V.Y.; Kholkin, A.L. Investigation of physical properties of diphenylalanine peptide nanotubes having different chiralities and embedded water molecules. Ferroelectrics 2018, 525, 168-177. [CrossRef]

43. Dayarian, S.; Kopyl, S.; Bystrov, V.; Correia, M.R.; Ivanov, M.S.; Pelegova, E.; Kholkin, A. Effect of the Chloride Anions on the Formation of Self-Assembled Diphenylalanine Peptide Nanotubes. IEEE Trans. Ultrason. Ferroelectr. Freq. Control 2018, 65, 1563-1570. [CrossRef]

44. Zelenovskiy, P.; Yuzhakov, V.; Nuraeva, A.; Kornev, M.; Shur, V.Y.; Kopyl, S.; Kholkin, A.; Vasilev, S.; Tofail, S.A.M. The Effect of Water Molecules on Elastic and Piezoelectric Properties of Diphenylalanine Microtubes. IEEE Trans. Dielectr. Electr. Insul. 2020, 27, 1474-1477. [CrossRef]

45. Guo, C.; Luo, Y.; Zhou, R.; Wei, G. Probing the Self-Assembly Mechanism of Diphenylalanine-Based Peptide Nanovesicles and Nanotubes. ACS Nano 2012, 6, 3907-3918. [CrossRef]

46. Kholkin, A.; Amdursky, N.; Bdikin, I.; Gazit, E.; Rosenman, G. Strong piezoelectricity in bioinspired peptide nanotubes. ACS Nano 2010, 4, 610-614. [CrossRef] [PubMed]

47. Hereida, A.; Bdikin, I.; Kopyl, S.; Mishina, E.; Semin, S.; Sigov, A.; German, K.; Bystrov, V.; Gracio, J.; Kholkin, A.L. Temperaturedriven phase transformation in self-assembled diphenylalanine peptide nanotubes. J. Phys. D Appl. Phys. 2010, $43,462001$. [CrossRef]

48. Bdikin, I.; Bystrov, V.S.; Delgadillo, I.; Gracio, J.; Kopyl, S.; Wojtas, M.; Mishina, E.; Sigov, A.; Kholkin, A.L. Polarization switching and patterning in self-assembled peptide tubular structures. J. Appl. Phys. 2012, 111, 074104. [CrossRef]

49. Reches, M.; Gazit, E. Controlled patterning of aligned self-assembled peptide nanotubes. Nat. Nanotechnol. 2006, 1, 195-200. [CrossRef] [PubMed]

50. Silva, R.F.; Araújo, D.R.; Silva, E.R.; Ando, R.A.; Alves, W.A. L-diphenylalanine microtubes as a potencial drug-delivery system: Characterization, release kinetics, and cytotoxicity. Langmuir 2013, 29, 10205-10212. [CrossRef]

51. Reches, M.; Gazit, E. Casting metal nanowires within discrete self-assembled peptide nanotubes. Science 2003, 300, 625-627. [CrossRef] 
52. Nguyen, V.; Zhu, R.; Jenkins, K.; Yang, R. Self-assembly of diphenylalanine peptide with controlled polarization for power generation. Nat. Commun. 2016, 7, 13566. [CrossRef]

53. Emtiazi, G.; Zohrabi, T.; Lee, L.Y.; Habibi, N.; Zarrabi, A. Covalent diphenylalanine peptide nanotube conjugated to folic acid/magnetic nanoparticles for anti-cancer drug delivery. J. Drug Deliv. Sci. Technol. 2017, 41, 90-98. [CrossRef]

54. Gupta, S.; Singh, I.; Sharma, A.K.; Kumar, P. Ultrashort Peptide Self-Assembly: Front-Runners to Transport Drug and Gene Cargos. Front. Bioeng. Biotechnol. 2020, 8, 504. [CrossRef]

55. Marchesan, S.; Vargiu, A.V.; Styan, K.E. The Phe-Phe Motif for Peptide Self-Assembly in Nanomedicine. Molecules 2015, 20, 19775-19788. [CrossRef]

56. Bystrov, V.S.; Coutinho, J.; Zelenovskiy, P.; Nuraeva, A.; Kopyl, S.; Zhulyabina, O.; Tverdislov, V. Structures and properties of the self-assembling diphenylalanine peptide nanotubes containing water molecules: Modeling and data analysis. Nanomaterials 2020, 10, 1999. [CrossRef]

57. Bystrov, V.S.; Coutinho, J.; Zhulyabina, J.A.; Kopyl, S.A.; Zelenovskiy, P.S.; Nuraeva, A.S.; Tverdislov, V.A.; Filippov, S.V.; Kholkin, A.L.; Shur, V.Y. Modeling and physical properties of diphenylalanine peptide nanotubes containing water molecules. Ferroelectrics 2021, 574, 78-91. [CrossRef]

58. Tamamis, P.; Adler-Abramovich, L.; Reches, M.; Marshall, K.; Sikorski, P.; Serpell, L.; Gazit, E.; Archontis, G. Self-assembly of phenylalanine oligopeptides: Insights from experiments and simulations. Biophys. J. 2009, 96, 5020-5029. [CrossRef] [PubMed]

59. Zheng, Y.; Mao, K.; Chen, S.; Zhu, H. Chirality Effects in Peptide Assembly Structures. Front. Bioeng. Biotechnol. 2021,9 , 703004. [CrossRef] [PubMed]

60. Müller, U. Symmetry Relationships between Crystal Structures. Applications of Crystallographic Group Theory in Crystal Chemistry; University Press: Oxford, UK, 2013.

61. Hahn, T. (Ed.) International Tables for Crystallography. Volume A: Space-Group Symmetry; Springer: Berlin/Heidelberg, Germany, 2005.

62. HyperChem 8. Tools for Molecular Modeling. Professional Edition for Windows AC Release 8.0 USB (on CD); Hypercube. Inc.: Gainesville, FL, USA, 2011.

63. The Cambridge Crystallographic Data Centre (CCDC). Available online: https://www.ccdc.cam.ac.uk/ (accessed on 30 August 2021).

64. VASP (Vienna Ab initio Simulation Package). Available online: https://www.vasp.at/ (accessed on 30 August 2021).

65. CCDC Mercury. Available online: https://www.ccdc.cam.ac.uk/solutions/csd-system/components/mercury/ (accessed on 30 August 2021).

66. Open Babel. Available online: https://openbabel.org/docs/dev/Installation/install.html (accessed on 30 August 2021). 